\title{
Intuição intelectual de si: breve análise da crítica de Schelling ao dogmatismo de Espinosa e da aproximação entre dogmatismo e criticismo
}

\author{
Intellectual intuition of self: a brief analysis of Schelling's critique of \\ Spinoza's dogmatism and the approximation of dogmatism and criticism
}

\author{
ANGELIANA PATRÍCIA DE SOUZA ${ }^{1}$
}

\begin{abstract}
Resumo: O presente artigo tem o intuito de analisar a crítica de Schelling às escolas do dogmatismo e criticismo sobre a possibilidade do ser humano alcançar o conhecimento de si. Para Espinosa, pela imanência com a substância, o homem pode conhecer verdadeiramente; contudo, Schelling define essa intuição intelectual de si (do homem) como tendo sido objetivada inadvertidamente, já que, desse modo, o homem coloca-se a pensar considerado inicialmente como objeto. $\mathrm{O}$ autor também pondera a interpretação à crítica kantiana, já que ela possibilitou a existência de todos os sistemas, assim como Kant expôs, entretanto, sem fundar, com isso, um novo sistema. Nesse sentido, o criticismo se se funda como sistema e traz para alvo último do filosofar o incondicionado como praticamente alcançável, se igualando ao dogmatismo, já que ambos os sistemas se identificam na busca do absoluto.
\end{abstract}

Palavras-chave: Criticismo. Dogmatismo. Intuição intelectual. Conhecimento de si.

Abstract: This article aims to analyze Schelling's critique of the schools of dogmatism and criticism about the possibility of the human being to achieve self - knowledge. For Spinoza, by immanence with substance man can truly know; however, Schelling defines this intellectual intuition of himself (of man) as having been inadvertently objectified, since in this way man puts himself to think initially considered as an object. The author also ponders interpretation to Kantian criticism, since it made possible the existence of all systems, as Kant did, however, without establishing a new system. In this sense, criticism, if founded as a system and brings to the ultimate goal of philosophizing the unconditioned as practically attainable, is equated with dogmatism, since both systems identify themselves in the search for the absolute.

Keywords: Criticism. Dogmatism. Intellectual intuition. Self-knowledge.

\section{Introdução}

O presente trabalho tem como objeto a crítica schellinguiana sobre a possibilidade do ser humano alcançar o conhecimento de si a partir das escolas do criticismo e do dogmatismo. No texto Cartas Filosóficas sobre o Dogmatismo e o Criticismo, Schelling desenvolve uma crítica à abordagem dogmática desenvolvida por Espinosa, bem como, à interpretação da obra kantiana Crítica da Razão Pura. Para Schelling, tanto o criticismo quanto o dogmatismo trazem o mesmo problema: levar à identidade absoluta, mesmo que de modo diferente, por via de anulação, seja do objeto, seja do sujeito que conhece. A análise de Schelling se baseia nas obras de

\footnotetext{
${ }^{1}$ Possui graduação em Psicologia pela Faculdade de Ciências Aplicadas de Cascavel (2014). É acadêmica do Programa de Pós-Graduação Stricto sensu (Mestrado em Filosofia da UNIOESTE). Email: angeliana2@gmail.com.
} 
Espinosa e de Kant, de modo que, inicialmente, para expor como a teoria espinosana entende ser possível uma intuição intelectual, recorrerei à Ética e, em seguida, à Crítica da Razão Pura a fim de apresentar, brevemente, o modo pelo qual a teoria kantiana admite a possibilidade do conhecimento de si do sujeito (seja teórico, seja praticamente), fazendo isso à luz da compreensão dessas teorias por Schelling.

\section{Espinosa e a possibilidade de conhecer verdadeiramente através da imanência com a substância.}

Na Ética, o homem foi definido por Espinosa como um modo finito que possui sua existência em uma substância única e infinita, e que também é por ela concebido. Nada pode existir fora dela, pois ela é a causa única de tudo o que existe, inclusive de si mesma. Conforme descreve Espinosa, a essência da substância envolve necessariamente a existência, ou seja, o existir é característica de sua própria natureza.

A essência infinita e eterna da substância é exprimida através de seus atributos que, por pertencerem a ela, são igualmente infinitos e eternos, e não partes dela, pois ela é indivisível tal como as características que também a exprimem.

Diferentemente do entendimento de Descartes, para Espinosa o ser humano é resultado de dois atributos da substância - do atributo pensamento e do atributo extensão. A composição humana inclui uma mente e um corpo resultantes destes atributos, conforme exposto no escólio da preposição 7 , na segunda parte do livro:

Antes de prosseguir convém relembrar aqui o que demonstramos antes: que tudo o que pode ser percebido por um intelecto infinito como constituindo a essência de uma substância pertence a uma única substância apenas e, consequentemente, a substância pensante e a substância extensa são uma só e a mesma substância, compreendida ora sob um atributo, ora sob o outro. (ESPINOSA, 2009, p. 28).

O corpo e a mente estão em conformidade um com o outro. De acordo com Silva (2011) as ideias desenvolvidas pela substância pensante - mente correspondem a desdobramentos de acontecimentos no corpo.

O corpo é quem possibilita esse conhecimento da substância extensa e consequentemente dele mesmo, tendo em vista que é por ele que percebemos o mundo e nos percebemos. No entanto, apenas a substancia pensante desenvolve ideias sobre esses desdobramentos do corpo, apenas pela mente são possíveis o conhecimento e a percepção deste corpo.

A mente tem a função de pensar o corpo, fazendo dele seu objeto, e para que isso ocorra ela é internamente ligada a ele. Essa relação interna entre a mente e o corpo decorre de ser da natureza dela pensá-lo, assim como é da natureza do corpo ser o objeto a ser pensado. A mente é definida como ideia do corpo. (SILVA, 2011) 
A união entre esses dois atributos ocorre porque o corpo existente é o objeto da mente humana. A mente é uma coisa pensante e, visto que o pensamento é um atributo, ela é parte do entendimento infinito da substância. Por ser uma coisa pensante, a mente forma conceitos, definidos na Ética como ideias:

A essência do homem é constituída por modos definidos dos atributos de Deus, e certamente, por modos do pensar, dentre todos os quais, a ideia é, por natureza, o primeiro. E existindo a ideia, os outros modos devem existir no mesmo indivíduo. É, assim, uma ideia que, primeiramente, constitui o ser da mente humana. Mas não a ideia de uma coisa inexistente, pois, então, não se poderia dizer que a própria ideia existe. Trata-se, portanto, da ideia de uma coisa existente em ato. (ESPINOSA, 2009, p. 59).

A ideia é um conceito formado pela mente enquanto coisa pensante. Diz Espinosa (2009, p. 61): a "[...] mente humana é a ideia de uma coisa singular existente em ato", logo, há uma identificação entre a mente humana e a ideia formada pelo atributo pensamento. Nesse sentido, a mente humana é ideia de uma coisa singular existente em ato, ou seja, uma coisa finita, o corpo.

A ideia da mente e a do corpo humano originam-se do pensamento, como atributo da substância, portanto, tal ideia também existe na substância; desse modo, há uma relação entre o conhecimento divino e o conhecimento humano. Neste sentido, o conhecimento humano não é isolado da verdade divina (da substância), pois todas as ideias da mente e do corpo humanos existem igualmente no intelecto divino de forma imanente. Observa Espinosa (2009, p. 61):

Disso se segue que a mente humana é uma parte do intelecto infinito de Deus. E, assim, quando dizemos que a mente humana percebe isto ou aquilo não dizemos senão que Deus, não enquanto é infinito, mas enquanto é explicado por meio da natureza da mente humana, ou seja, enquanto constitui a essência da mente humana, tem esta ou aquela ideia. E quando dizemos que Deus tem esta ou aquela ideia, não enquanto ele constitui a natureza da mente humana apenas, mas enquanto tem, ao mesmo tempo que [a ideia que é] a mente humana, também a ideia de outra coisa, dizemos, então, que a mente humana percebe essa coisa parcialmente, ou seja, inadequadamente.

É pela identificação da mente humana com o intelecto infinito de Deus - a substância - que é possibilitado a ela (mente) ter um conhecimento verdadeiro, definido por Spinoza como adequado, afastando com isso o pensamento filosófico tradicional de que a mente não poderia conhecer verdadeiramente ${ }^{2}$ em razão de sua ligação com o corpo.

\footnotetext{
${ }^{2} \mathrm{O}$ termo "conhecimento verdadeiro" é aqui empregado para tratar do conhecimento adequado, ou seja, aquele proveniente da substância. Conforme dispõe Espinosa (2009, p. 11): "O que, aliás, deve ser
} 
No entanto, tal afirmação significa que é possível conhecer verdadeiramente através da substância, mas não que esse conhecimento da mente seja sempre verdadeiro, pois ela tem, também, um conhecimento confuso do seu corpo e de si mesma, resultante de ideias que são meramente imaginativas e, por isso, inadequadas. (SILVA, 2011).

Espinosa propõe três gêneros para explicar os diferentes níveis do conhecimento humano: o imaginativo, o racional e o intuitivo. O conhecimento imaginativo ocorre porque a mente humana conhece seu corpo e os corpos exteriores só de maneira confusa e mutilada, já que a mente, ao perceber o corpo através das afecções pelas quais é afetado, pode vir a compreender tais afecções de modo equivocado, chamando-as de imagens. Nesse sentido, enquanto tem ideia só das afeç̧ões do corpo, e não da totalidade que integra todo o existir, a mente faz ideia apenas do que afeta o corpo e com isso permanece na ignorância a respeito das causas dessas imagens; por isso o conhecimento imaginativo é parcial e inadequado. Trata-se de um conhecimento por experiência errática, pois depende apenas da imagem formada pelo corpo, mostrando-se fragmentado e confuso por ter seu início “[...] a partir de signos; por exemplo, por ter ouvido ou lido certas palavras, nós nos recordamos das coisas e delas formamos ideias semelhantes àquelas por meio das quais imaginamos as coisas" (ESPINOSA, 2009, p. 81).

Por sua vez, no segundo nível, o conhecimento racional se deriva de ideias comuns a todos os homens, as quais são percebidas adequadamente por todos. Uma ideia só será inadequada se estiver referida apenas a ideia singular de alguém; mas se a ideia é comum a todas as coisas e existe igualmente na parte e na totalidade, então ela existe na substância; e porque esta constitui a mente humana, a ideia é necessariamente adequada.

Espinosa apresenta o conhecimento intuitivo como conhecimento de terceiro nível, também chamado de ciência intuitiva, que se funda no próprio conhecimento da substância à qual, de forma imanente, se liga à mente humana que, por essa razão, pode conhecer verdadeiramente. A essência infinita da substância pode ser conhecida por todos, pois tudo existe nela, inclusive o corpo e a mente humana; através da imanência com seus atributos pode-se deduzir muitas coisas e conhecer adequadamente partindo da "ideia adequada da essência formal de certos atributos de Deus para chegar ao conhecimento adequado da essência das coisas" (ESPINOSA, 2009, p. 81). Complementa Espinosa (2009, p. 74):

igualmente dito a respeito de qualquer uma das partes do próprio indivíduo que é o corpo humano. Assim, o conhecimento de cada uma das partes que compõe o corpo humano existe em Deus, enquanto ele é afetado de muitas ideias de coisas, e não enquanto tem exclusivamente a ideia do corpo humano, isto é, a ideia que constitui a natureza da mente humana. Portanto, a mente humana não envolve o conhecimento adequado das partes que compõem o corpo humano." 
Assim, o conhecimento de cada uma das partes que compõe o corpo humano existe em Deus, enquanto ele é afetado de muitas ideias de coisas, e não enquanto tem exclusivamente a ideia do corpo humano, isto é, a ideia que constitui a natureza da mente humana.

O filósofo ainda escreve:

A mente humana tem ideias por meio das quais percebe a si própria, o seu corpo e os corpos exteriores, como existentes em ato. Portanto, ela tem um conhecimento adequado da essência eterna e infinita de Deus. (ESPINOSA, 2009, p. 88).

A substância é afetada de muitas ideias e não faz ideia apenas do corpo. Se o homem deduzir a partir do conhecimento adequado da substância ele poderá conhecer verdadeiramente. A única forma de privar a mente de conhecimento verdadeiro é através do conhecimento imaginativo, pois este é a causa da falsidade. Quando uma ideia se origina a partir de um conhecimento parcial e confuso, todo o restante que se segue dele não será verdadeiro; essa afirmação se refere à impossibilidade de a mente conhecer adequadamente através dos conhecimentos racional e intuitivo, no caso de que estes pudessem se referir a ideias imaginativas.

Conforme afirma Silva (2011), a responsabilidade pelo erro em tornar o conhecimento falso não reside no objeto, mas na mente humana, pois esta é a responsável pelas ideias se tornarem inadequadas; o objeto apenas apresenta imagens conforme foi afetado e assim é conhecido, mesmo que limitadamente. Deste modo, o erro está na articulação que a mente faz dos objetos que ela conhece, sendo que esse encadeamento errôneo das ideias que ela possui impossibilita o conhecimento que poderia ser alcançado, se o encadeamento tivesse ocorrido da forma correta.

A esse terceiro gênero de conhecimento Espinosa atribui o mais alto grau a que as ideias podem se elevar e tem como fundamento o próprio conhecimento da substância. Esse conhecimento surge através da experiência imediata que o ser humano tem dos atributos da substância que o constituem, sem interferência do conhecimento sensível, imaginativo; assim, tudo que é proveniente deste conhecimento imediato não pode ser equivocado nem viciado pelas imaginações.

\section{Crítica de Schelling à intuição intelectual de Espinosa}

A noção de intuição intelectual trazida e apresentada por Schelling remonta ao gênero superior de conhecimento de Espinosa, em que o conhecimento decorre de uma ideia considerada em si mesma, em ligação com a substância divina. Essa intuição permite o acesso ao eu absoluto e indica a identidade total com o fundamento das coisas. (BARBOZA, 2005). 
Nas Cartas sobre o dogmatismo e criticismo, Schelling define intuição intelectual como a mais imediata das experiências, sendo diferenciada da intuição sensível por esta derivar de uma experiência mediata. Uma experiência mediata é aquela que decorre de outra, que não ocorre nem conhece por si mesma, mas por intermédio de outra. É a chamada intuição sensível, pois conhece através dos sentidos, através das afecções corporais, ou seja, por meio do conhecimento imaginativo para Spinoza.

Por sua vez, a intuição intelectual parte de uma experiência imediata, produzida por si mesma, sem interferência dos sentidos corporais e, por não ser uma experiência derivada de nenhum objeto, ela independe de toda causalidade objetiva.

Através do absoluto a mente humana pode atingir o conhecimento verdadeiro. Para Espinosa, é possível um conhecimento verdadeiro de si mesmo ao atingir o terceiro gênero do conhecimento, em que o absoluto não é tido como objeto devido à identificação dele com a substância. O conhecimento adequado de si surge através da experiência imediata, que temos por meio dos atributos da substância que nos constituem. Nesse ponto, Schelling inicia sua crítica ao modo de pensar espinosano, comparando-o a um dogmatismo cego.

Na Oitava Carta ele argumenta que o início de todo "delírio místico" dogmático se dá pela necessidade de certos pensadores proporem o pensamento de si (ou conhecimento de si) de um modo tal que, ao racionalizarem o acesso do sujeito a si mesmo, partem de um fundamento inacessível, alcançado por atitude de "místico". Schelling atribui a Espinosa esse lugar, de haver desenvolvido um pensamento místico do ponto de vista do acesso a seu fundamento.

Espinosa admite ser possível chegar a um conhecimento verdadeiro de si pela identificação entre o eu que intui e o eu intuído. No entanto, para Schelling, trata-se aí de uma identificação alcançada através de uma intuição intelectual objetivada: o eu intuía a si mesmo só a partir da admissão de um objeto absoluto, a substância, e não por uma experiência imediata. Schelling mostra que enquanto essa última pode ser demonstrada desde um modo de acesso ao absoluto, a primeira (intuição objetivada) não pode ser conceituada sem eliminar com isso, ao mesmo tempo, o sujeito que coloca a exigência dessa conceituação. A despeito de Espinosa denominar seu modo de acesso ao absoluto também por meio de um tipo de experiência em que o sujeito o atinge através de si mesmo, pela própria experiência imediata, essa última ocorre no plano exclusivamente intuitivo.

Todavia, ao contrário do que Schelling entende por intuição intelectual, Espinosa crê que ao intuir a si mesmo ele não deixou de se considerar objeto de conhecimento. Nota Schelling (1973, p. 198): 
Essa intuição intelectual se introduz, então, quando deixamos de ser objeto para nós mesmos e quando, retirado em si mesmo, o eu que intui é idêntico ao eu intuído. Nesse momento da intuição, desaparecem para nós tempo e duração: não somos nós que estamos no tempo, mas o tempo - ou antes, não ele, mas a pura eternidade absoluta - que está em nós. Não somos nós que estamos perdidos na intuição do mundo objetivo, mas é este que está perdido em nossa intuição.

No absoluto acaba toda a passividade, pois a substância é causa de si mesma, um ser autossuficiente que age apenas por liberdade absoluta, segundo sua essência própria, e não está por isso limitado a nada. Esse posicionamento, defendido já por Espinosa no sentido de que a essência da substância está compreendida nela mesma, enquanto que a essência do homem esta compreendida em outra coisa "[...] cujo conceito é formado por meio do conceito da coisa na qual existe" (ESPINOSA, 2009, p. 9), acentua que a verdade não está já nele próprio, mas que por isso o sujeito pensa a si mesmo; é deste retorno a si do sujeito que surge uma consciência.

O pensar sobre si mesmo remete a uma atividade para qual se é objeto. Só que essa proposição dá azo a duas interpretações: ou remete à substância, como agindo com liberdade absoluta, em que a verdade está contida nela própria, acarretando com isso não estar sendo pensada nenhuma autoconsciência, já que ela não precisa pensar a si mesma pois tudo se explica a partir de sua própria essência. Aparentemente, aqui o sujeito se dissolve em algo maior, que lhe precede necessariamente e é mais real que ele próprio. Ou remete à consciência, como agindo com liberdade absoluta, em que a verdade contida nela é produzida por ela própria, implicando nisso que a autoconsciência é necessária para o sujeito pensar a si mesmo, já que nele não há uma essência substancial previamente constituída. Aqui a consciência se torna objeto para si mesmo, e o sujeito não se dissolve nessa reflexão.

Como limitação do absoluto, o ser humano está condicionado a agir pelo conhecimento da lei racional; o absoluto, por sua vez, não é condicionado a nada, age apenas em conformidade consigo mesmo, é incondicionado.

Ocorre, porém, que a existência humana não pode ser pensada senão em decorrência de ser limitada pelo absoluto no sujeito. Se se leva adiante esse modo de intuição intelectual, para além da consideração da razão como uma limitação do absoluto pelo sujeito (limitação interna), então tem-se uma passagem para o "nãoser": aqui o sujeito sai de si (de sua esfera de autolimitação) que condiciona a existência humana e vai em direção ao radicalmente ilimitado; trata-se de um momento de anulação do eu existente com vistas a um tipo de unificação com o absoluto, em que tudo o que é subjetivo desaparece em favor do que é objetivo, para dar lugar exclusivamente à extensão infinita, sem retorno a si mesmo do sujeito. 


\section{Anulação de si mesmo: a aproximação entre dogmatismo e criticismo}

Para Schelling, o dogmatismo e o criticismo possuem um ponto de unificação. Trata-se do fato de ambos considerarem a existência de um princípio absoluto superior ao saber humano, mas ao qual cada um visa atingir por um tipo de específico de anulação: ou do objeto ou de si mesmo.

Ora, Kant distinguiu na Crítica da Razão Pura dois tipos de intuição. A primeira trata-se de uma intuição e é definida pelo autor como sendo primitiva, ou seja, não depende de nada além do próprio ser que age e conhece espontaneamente. Para o autor, não temos o mínimo acesso a essa forma de intuição intelectual, pois essa forma de intuir não é humana, mas apenas encontrada no ser divino. Já a segunda intuição não é espontânea, mas deriva da sensibilidade, própria do ser que determina sua existência pela relação com os objetos dados. Essa é a única forma de intuição admitida para o homem.

Na medida em que essa forma de intuição é a única possível, ela se refere ao único modo de conhecimento que permite a relação imediata com o objeto; fica negada aqui a possibilidade de uma intuição intelectual.

Para Kant (2001, p. 104), o homem "se percebe intuitivamente, não como se representara a si mesmo imediatamente e em virtude de sua espontaneidade, mas segundo a maneira pela qual ele é intuitivamente afetado, e, por conseguinte, tal como ele se oferece a si próprio e não como é". Desse modo, o conhecimento que tem de si mesmo não é espontâneo, mas depende da maneira de como ele é afetado na sensibilidade.

Ainda de acordo com o autor, o conhecimento humano tem duas origens, a sensibilidade e o entendimento, que possivelmente emanam de uma mesma raiz desconhecida. A sensibilidade fornece intuições, mas é através do entendimento que elas são pensadas. Assim, as condições sob as quais os objetos são dados influenciam em como eles são pensados pela mente humana, logo o homem não conhece as coisas tal como são, mas como eles se mostram (fenômenos).

Toda a intuição sensível aparece no tempo e tudo que o homem intui por ser afetado por algo que aparece no espaço. Assim, tudo que é cognoscível a ele está no espaço e tempo. (DUDLEY, 2007). Nesse sentido, só é possível ao homem uma intuição sensível, mas Kant admite a possibilidade de uma intuição intelectual fora dele, a qual não pode ser acessada, conforme se verifica no trecho a seguir:

Não querendo considerar o espaço e o tempo formas objetivas de todas as coisas, resta apenas convertê-las em formas subjetivas do nosso modo de intuição, tanto externa como interna; modo que se denomina sensível, porque não é originário, quer dizer, não é um modo de intuição tal, que por ele seja dada a própria existência do objeto da intuição (modo que se nos afigura só poder pertencer ao 
Ser supremo), antes é dependente da existência do objeto e, por conseguinte, só possível na medida em que a capacidade de representação do sujeito é afetada por esse objeto. (KANT, 2001, p. $114)$.

Nas Cartas, Schelling define que esse seria o ponto de unificação entre criticismo e dogmatismo, um ser absoluto, que não pode ser objeto do saber humano, mas apenas objeto da liberdade; logo, está acima do saber humano e, conforme identifica a teoria kantiana, inacessível.

No entanto, se esse saber absoluto for interpretado como acessível, então o criticismo tem de ser visto como tendo estabelecido, do ponto de vista práticomoral, o conhecimento absoluto como realizável (como conhecimento prático), com cuja admissão, entretanto, ele passa a se apresentar como dogmatismo, pois nesse caso ele dá por concluída a tarefa de pensar o absoluto, ao admiti-lo tê-lo já apreendido e abarcado; o que é impossível, porque tal conceito não é abarcável teoricamente.

Na Nona Carta, Schelling assevera que se fossem considerados como sistemas completos e perfeitos, tanto o criticismo como o dogmatismo teriam de ter suprimido a tensão existente entre sujeito e objeto, eliminando com isso a contradição e levando à identidade absoluta. Só que em decorrência disso todo o conhecimento objetivo estaria perdido para o sujeito, pois por essa unificação e identificação a consciência do sujeito seria definitivamente suprimida pelo infinito conjuntamente com a do objeto.

Segundo o autor, a interpretação que deve ser dada à Crítica da Razão Pura é a de que a existência desses sistemas foi condicionada pela razão crítica que, em si mesma, não visou fornecer um sistema novo, mas só um método para dois sistemas possíveis: o criticismo, que visa representar o conhecimento verdadeiro como alcançável em seu sistema, e o dogmatismo, que não pode salvar-se da acusação de conduzir a um delírio místico.

Nesse sentido, o autor das Cartas propõe para função da crítica da razão servir de cânon para preparar a subsistência de dois sistemas possíveis, ainda que diretamente contrapostos, deduzidos, é certo, da ideia indeterminada de um método geral para todos os sistemas. Como havia dito Kant (2001, p. 81):

Desta investigação tratamos presentemente. Não podemos verdadeiramente chamar-lhe doutrina, mas apenas crítica transcendental, porquanto a sua finalidade não é o alargamento dos próprios conhecimentos, mas a sua justificação, e porque deve fornecer-nos a pedra de toque que decide do valor ou não valor de todos os conhecimentos a priori.

A finalidade da crítica não é a de alcançar o saber absoluto, mas de corrigir os conhecimentos obtidos pelos sistemas, principalmente no que se refere ao 
dogmatismo e sua valoração dos conhecimentos a priori como conhecimentos verdadeiros.

\section{Conclusão}

Da leitura das Cartas conclui-se que a maneira de Schelling conduzir as conclusões a que chegou sobre o criticismo remonta criticamente à teoria de Espinosa.

Para Schelling, Espinosa apresenta uma contradição em sua teoria: ele identifica o conhecimento verdadeiro como o que é livre de toda causalidade objetiva sem deixar de pensar a si mesmo (sujeito) como dependente do ponto de vista objetivo, assentado na substância, à qual ele acede por um processo intuitivo diretamente objetivo. Pela objetivação dessa forma de intuição intelectual o ser (sujeito) que intui, mesmo que idêntico ao objeto absoluto, permanece possuindo só uma visão abstrata e objetiva de si mesmo.

Por sua vez, Kant não admite a possibilidade dessa intuição, pois para ele o homem só conhece através da sensibilidade e do entendimento, por um modo de intuição que nunca é espontâneo ou que produz o objeto por liberdade absoluta. Não há em Kant um conhecimento absoluto, pois para chegar a esse conhecimento o homem teria de estar fora das condições de espaço e tempo; logo, seria impossível alcançá-lo sem anular sua existência, o que, consequentemente, o impossibilitaria de intuir.

Ao refletir sobre a possibilidade do criticismo tornar-se sistema, Schelling demonstra a aproximação do criticismo com o dogmatismo, pois, se, ao contrario da teoria kantiana, o criticismo for interpretado como um sistema que apresenta o saber absoluto como algo realizável no sujeito, essa forma de interpretação admitiria a realização plena da consciência de si e, com isso, o sujeito desapareceria no infinito, como ocorre, pelo motivo inverso, com o dogmatismo.

\section{Referências}

BARBOSA, J. Infinitude subjetiva e estética: natureza e arte em Schelling e Schopenhauer. São Paulo: Unesp, 2005.

DUDLEY, W. Idealismo alemão. Petrópolis, RJ: Vozes, 2007.

ESPINOSA, B. Ética. Belo Horizonte: Autêntica, 2009.

KANT, I. Crítica da razão pura. 5.ed. Lisboa: Fundação Calouste Gulbenkian, 2001.

SCHELLING, F. W. "Cartas filosóficas sobre o dogmatismo e o criticismo”. In: FICHTE, J.G. SCHELLING, F.V. Escritos filosóficos. São Paulo: Abril Cultural, 1973.

SILVA, E. C. "A relação corpo-mente: A mente como ideia do corpo na Ética de Benedictus de Spinoza”, in: Rev. Conatus - Filosofia de Spinoza. vol 5, n. 9, p. 19-24, 2011. 
Intuição intelectual de si: breve análise da crítica de Schelling ao dogmatismo de Espinosa e da aproximação entre dogmatismo e criticismo

Submissão: 05.10.2018 / Aceite: 11.12.2018. 